\title{
A traumatic tale of two cities: does EMS level of care and transportation model affect survival in patients with trauma at level 1 trauma centres in two neighbouring Canadian provinces?
}

\author{
Colin Rouse, ${ }^{1,2}$ Jefferson Hayre, ${ }^{1,3}$ James French, ${ }^{4,5}$ Jacqueline Fraser, ${ }^{6}$ Ian Watson, ${ }^{5}$ \\ Susan Benjamin, ${ }^{5}$ Allison Chisholm, ${ }^{5}$ Beth Sealy, ${ }^{7}$ Mete Erdogan, ${ }^{7}$ Robert S Green, 7,8 \\ George Stoica, ${ }^{9}$ Paul Atkinson ${ }^{4,5}$
}

'Dalhousie Medicine New Brunswick, Saint John, New Brunswick, Canada

${ }^{2}$ Department of Family Medicine, Dalhousie University, Saint John Regional Hospital, Saint John, New Brunswick, Canada ${ }^{3}$ Department of Family Medicine, McGill University, Jewish General Hospital, Montreal, Quebec, Canada ${ }^{4}$ Department of Emergency Medicine, Dalhousie University, Saint John Regional Hospital, Saint John, New Brunswick, Canada

New Brunswick Trauma Program, Saint John, New Brunswick, Canada

${ }^{6}$ Department of Emergency Medicine, Saint John Regiona Hospital, Saint John, New Brunswick, Canada

${ }^{7}$ Nova Scotia Department of Health and Wellness, Trauma Nova Scotia, Halifax, Nova Scotia, Canada

${ }^{8}$ Department of Critical Care Dalhousie University, Halifax Nova Scotia, Canada

${ }^{9}$ Research Services, Horizon Health Network, Saint John New Brunswick, Canada

\section{Correspondence to}

Dr Colin Rouse, Department of Family Medicine, Dalhousie University, Saint John Regional Hospital, Saint John, NB E2K 5E2, Canada;

colin.rouse@dal.ca

Received 7 September 2016 Revised 5 August 2017 Accepted 11 October 2017 Published Online First 4 November 2017

\section{Check for updates}

To cite: Rouse C, Hayre J, French J, et al. Emerg Med J 2018:35:83-88.

\section{ABSTRACT \\ Background Two distinct Emergency Medical} Services (EMS) systems exist in Atlantic Canada. Nova Scotia operates an Advanced Emergency Medical System (AEMS) and New Brunswick operates a Basic Emergency Medical System (BEMS). We sought to determine if survival rates differed between the two systems.

Methods This study examined patients with trauma who were transported directly to a level 1 trauma centre in New Brunswick or Nova Scotia between 1 April 2011 and 31 March 2013. Data were extracted from the respective provincial trauma registries; the lowest common Injury Severity Score (ISS) collected by both registries was $I S S \geq 13$. Survival to hospital and survival to discharge or 30 days were the primary endpoints. A separate analysis was performed on severely injured patients. Hypothesis testing was conducted using Fisher's exact test and the Student's t-test.

Results 101 cases met inclusion criteria in New Brunswick and were compared with 251 cases in Nova Scotia. Overall mortality was low with $93 \%$ of patients surviving to hospital and $80 \%$ of patients surviving to discharge or 30 days. There was no difference in survival to hospital between the AEMS (232/251, 92\%) and BEMS (97/101, 96\%; OR 1.98, 95\% Cl 0.66 to 5.99; $p=0.34)$ groups. Furthermore, when comparing patients with more severe injuries (ISS $>24$ ) there was no significant difference in survival $(71 / 80,89 \%$ vs $31 / 33$, $94 \%$; OR $1.96,95 \%$ Cl 0.40 to $9.63 ; p=0.50$ ).

Conclusion Overall survival to hospital was the same between advanced and basic Canadian EMS systems. As numbers included are low, individual case benefit cannot be excluded.

\section{INTRODUCTION}

Injury is one of the leading causes of mortality and morbidity worldwide. ${ }^{1}$ In fact, traumatic injury is the leading cause of death among individuals between 1 and 44 years of age. ${ }^{2}$ More than 5 million people die each year as a result of injury, according to the WHO. ${ }^{1}$ The burden of traumatic injury goes beyond mortality. A study in Ontario, Canada, revealed that for each death due to injury there were 25 hospitalisations, 363 emergency room visits and 495 people left with functional impairment. ${ }^{3}$

\section{Key messages}

What is already known on this subject The literature to date comparing Basic (BEMS)and Advanced Emergency Medical Systems (AEMS) has yielded conflicting results regarding survival benefit. There remains no true consensus on the optimal level of prehospital care.

\section{What this study adds}

We compared survival rates for patients with trauma in two Canadian trauma centres, one of which uses BEMS and the other AEMS. Overall mortality rates were low, and no significant difference was found in survival between the two prehospital systems.

Emergency Medical Services (EMS) are a major contributor to trauma care in the prehospital setting. The transport and treatment provided to patients before arriving to hospital has been a topic of major study and discussion and has led to the adoption of various systems in different regions. The two major distinctions for paramedic-delivered EMS care in North America are the provision of Advanced Life Support (ALS) and Basic Life Support (BLS). While these terms often encompass a diverse spectrum of care in different regions, in general ALS is a sophisticated approach to prehospital care which includes invasive methods such as intubation, intravenous fluids and administration of medications. ${ }^{4}$ In comparison, BLS provides minimally invasive care and focuses on prompt transportation of the patient to the appropriate centre for care. There have been conflicting findings about the efficacy of ALS, which vary with many factors including the illness or injury being treated, transport time, the injury severity among others. ${ }^{5}$ Despite variable findings, there is some evidence that Advanced Care Paramedics (ACPs) are able to deliver superior care for certain patient groups compared with paramedics and nurses without advanced training. ${ }^{6}$ A major concern about ALS and critical care provision is that more time will be spent on scene administering ALS procedures and that this will cause a delay in 


\begin{tabular}{|ll|}
\hline Primary Care Paramedics & Advanced Care Paramedics \\
Primary patient assessment & Use of endotracheal airways \\
Automated external defibrillation & Mechanical ventilation \\
Peripheral IV cannulation & Intraosseous insertion \\
Airway devices not introduced & Manual defibrillation \\
endotracheally & Cardioversion \\
& Needle thoracostomy \\
& Administration of medication by IV or \\
& endotracheal tube. \\
\hline
\end{tabular}

Figure 1 Paramedic skill sets.

the transfer of patients to the appropriate hospital for potentially life-saving treatment such as surgery. ${ }^{7}$

The key questions for prehospital care are what meaningful interventions should be provided, who should be providing them and what transport platform should be used to improve patient outcomes? Current evidence remains mixed with only some research supporting ALS. ${ }^{8-10}$ In two meta-analyses, one looking at historical data and another focusing on more recent data, significant benefits were not consistently observed for patients with trauma receiving ALS. ${ }^{11} 12$

The organisation of prehospital care in Atlantic Canada varies considerably by province. This provides an opportunity to assess this natural experiment comparing data from two provinces with distinct EMS systems. The provinces of New Brunswick and Nova Scotia are significantly more rural than the areas studied in publications to date. It is, therefore, important to understand the effect of modern ALS and BLS care on patients with trauma in these settings. Further to our in-hospital analysis, ${ }^{13}$ this study aimed to determine whether patients were more likely to survive transport to the appropriate hospital in a Basic Emergency Medical System (BEMS) or an Advanced Emergency Medical System (AEMS), and to compare 30-day survival following injury.

\section{METHODOLOGY \\ Design}

We conducted an observational cohort study using aggregate registry data from the trauma registries of New Brunswick and Nova Scotia. The data were analysed in situ within each provincial Trauma Program. Results from both provinces were then pooled and compared. The trauma registries of New Brunswick and Nova Scotia each provide comprehensive data sets on patients who suffered significant injuries (Injury Severity Score (ISS) $\geq 13$ ). This is in accordance with the National Trauma Registry of Canada, which established an ISS $\geq 13$ as its inclusion criteria. Other aggregated data from computer-aided dispatch of Ambulance New Brunswick were used in order to capture patients who did not survive to hospital and were not included in the New Brunswick Trauma Registry. This step was not necessary in Nova Scotia as their dataset already captured this information.

\section{Study permissions and data protection}

All data processing was performed by personnel with current host institution data protection training, using encrypted media on a dedicated secure server in the host trauma program. Horizon Health Network is a registered data custodian for the New Brunswick Trauma Registry and uses systems that are compliant with current data protection legislation. ${ }^{14}$ The New Brunswick Trauma Program, Trauma Nova Scotia, Ambulance New Brunswick and Emergency Health Services in Nova Scotia approved aggregate data access. Additionally, departmental support was received from the Departments of Emergency Medicine at the
Saint John Regional Hospital and the Queen Elizabeth II Health Sciences Centre in Halifax.

\section{Setting}

Despite being relatively small when compared with Canada's largest cities, Halifax Nova Scotia and Saint John New Brunswick are major centres in Atlantic Canada. Halifax is the largest city in Nova Scotia and its regional municipality had a population of 390096 in $2011 .^{15}$ Similarly, Saint John is one of the largest cities in New Brunswick with a population of 127761 in its metropolitan area in $2011 .{ }^{15}$ Nova Scotia covers a land area of approximately $53000 \mathrm{~km}^{2}$ compared with New Brunswick with a land area of approximately $71000 \mathrm{~km}^{2}$ and the proportion of the population living in rural areas is 0.43 and 0.47 , respectively. ${ }^{15}$ The population density in the Halifax metropolitan area is $71 / \mathrm{km}^{2}$ which is slightly greater than the Saint John metropolitan area population density of $38 / \mathrm{km}^{2} .{ }^{15}$ The median age is the same in each province at 43.7 years and the median income of individuals in Nova Scotia is $\$ 27570$ compared with $\$ 26582$ in New Brunswick. ${ }^{15}$ Both provinces operate similar publicly funded healthcare systems. Each of these cities is home to the only adult level 1 trauma centre in their respective province. Despite their general similarities, two distinct EMS systems exist in these regions.

\section{Prehospital care structure}

Paramedics are designated as Primary Care Paramedics (PCPs), Advanced Care Paramedics (ACPs) or Critical Care Paramedics (CCPs) in these jurisdictions. While there was a mix of paramedic levels in each system during the study period, New Brunswick had adopted a BEMS which mandated the provision of BLS, with all practitioners operating at the PCP level. In the BEMS, care is delivered through a ground transport network of multilevel trauma centres. In contrast, Nova Scotia provides an AEMS where ACPs and CCPs deliver ALS to critically ill patients. The skill sets provided by each level of paramedic are in accordance with the Paramedic Association of Canada National Occupational Competency Profile. ${ }^{16} \mathrm{~A}$ summary of differences between PCP and ACP skill sets can be found in figure 1. Nova Scotia also operates a prehospital helicopter transportation service which includes CCPs, a respiratory therapist and critical care nurses. New Brunswick does not offer a helicopter EMS service. Both systems have written or interactive guidance as to the appropriateness of bypassing hospital for direct transport to level 1 trauma centres. In each system, there are patients with severe injuries who require stabilisation at level 2-5 trauma centres prior to being transported to the level 1 trauma centre.

\section{Participants}

Included in the study were all patients $>15$ years of age who suffered a kinetic injury according tothe following International Classification of Diseases $10^{\text {th }}$ revision (ICD-10) codes (V01W64, X85-Y09) with an ISS $\geq 13$, for whom an ambulance was called in the catchment areas of the level 1 trauma centres in each province. Interfacility transfer patients were excluded; only those transported from the scene directly to the level 1 trauma centre were included. Patients who received resuscitation but died on scene or on route to hospital were included in the data since they received clinical intervention. Excluded were any patients for whom EMS were called but no resuscitation was attempted at the scene as they did not survive to receive clinical intervention. Paediatric patients (age $\leq 15)$ were also excluded since they are treated at a specialised children's hospital in Nova Scotia. 
Table 1 Patient characteristics

\begin{tabular}{|c|c|c|c|}
\hline \multirow[b]{2}{*}{ Characteristic } & \multicolumn{3}{|c|}{ Emergency Medical System } \\
\hline & Basic & Advanced & $p$ Value \\
\hline ISS by category, n (\%) & $n=101$ & $n=251$ & \\
\hline $13-24$ & $68(67)$ & $171(68)$ & 0.90 \\
\hline$>24$ & $33(33)$ & $80(32)$ & 0.90 \\
\hline Overall & $n=101$ & $\mathrm{n}=251$ & \\
\hline Age, median (IQR) & $53(26-76)$ & $51(29.5-65)$ & 0.29 \\
\hline Gender, n (\%) male & $70(69)$ & $183(73)$ & 0.60 \\
\hline Type of injury, $n(\%)$ blunt & $95(94)$ & $236(94)$ & 1.00 \\
\hline ISS, median (IQR) & $18(16-25)$ & $19(16-26)$ & 0.064 \\
\hline \multicolumn{4}{|l|}{ External cause of injury, $n(\%)$} \\
\hline Fallst & $49(48)$ & $86(34)$ & 0.015 \\
\hline Transport accidents* & $35(35)$ & $132(53)$ & 0.003 \\
\hline Assaults & $9(9)$ & $26(10)$ & 0.84 \\
\hline Animate or inanimate forces $t$ & $8(8)$ & $7(3)$ & 0.041 \\
\hline \multirow[t]{2}{*}{ EMS SBP<90 mm Hg, n (\%) } & $\mathrm{n}=95$ & $n=183$ & \\
\hline & $8(8)$ & $16(9)$ & 0.52 \\
\hline \multirow[t]{2}{*}{ Scene GCS, median (IQR) } & $n=100$ & $n=232$ & \\
\hline & $15(13-15)$ & $15(12-15)$ & 0.53 \\
\hline \multirow[t]{2}{*}{ EMS shock index>0.7, n (\%) } & $\mathrm{n}=93$ & $n=203$ & \\
\hline & $31(33)$ & $76(37)$ & 0.52 \\
\hline Moderate injury & $n=68$ & $n=171$ & \\
\hline Age, median (IQR) & $48.5(22-73.5)$ & $50(28-64)$ & 0.80 \\
\hline Gender, $\mathrm{n}(\%)$ male & $47(69)$ & $118(69)$ & 1.00 \\
\hline ISS, median (IQR) & $16.5(14-18)$ & $17(14-19)$ & 0.10 \\
\hline \multirow[t]{2}{*}{ Scene GCS, median (IQR) } & $n=68$ & $n=161$ & \\
\hline & $15(6)$ & $15(6)$ & 0.49 \\
\hline \multirow[t]{2}{*}{ EMS shock index>0.7, n (\%) } & $n=63$ & $n=144$ & \\
\hline & $22(35)$ & $53(37)$ & 0.88 \\
\hline Severe injury & $n=33$ & $n=80$ & \\
\hline Age, median (IQR) & $59(35-78)$ & $51(36.5-70.3)$ & 0.23 \\
\hline Gender, $\mathrm{n}(\%)$ male & $23(70)$ & $65(81)$ & 0.21 \\
\hline ISS, median (IQR)† & $26(25-29)$ & $27(26-33)$ & 0.019 \\
\hline \multirow[t]{2}{*}{ Scene GCS, median (IQR) } & $\mathrm{n}=32$ & $\mathrm{n}=71$ & \\
\hline & $13(10)$ & $13(10)$ & 0.61 \\
\hline \multirow[t]{2}{*}{ EMS shock index>0.7, n (\%) } & $\mathrm{n}=30$ & $\mathrm{n}=59$ & \\
\hline & $9(30)$ & $23(39)$ & 0.49 \\
\hline
\end{tabular}

External cause of injury are defined by ICD-10 code.

Some analyses were completed with fewer observations than the total $\mathrm{n}$ for each system due to missing data (this is indicated by $n$ values in columns 2 and 3 ).

* Indicates strong significance $(p<0.01)$.

tIndicates moderate significance $(0.01<p<0.05)$.

GCS, Glasgow Coma Scale; ISS, Injury Severity Score; SBP, systolic blood pressure.

Data on patients injured between 1 April 2011 and 31 March 2013 and who met all eligibility criteria were extracted from the respective registries in each province.

\section{Outcomes}

The primary outcome measure of survival to hospital was defined using the pre-existing definition in the Nova Scotia Trauma Registry. The null hypothesis was that differences in prehospital care between New Brunswick and Nova Scotia do not affect survival to hospital in patients with an ISS $\geq 13$. Additionally, it was hypothesised that differences in prehospital care do not affect the composite outcome of discharge from hospital or 30-day survival in patients with an ISS $\geq 13$. The 30 -day mark is a standard measure of outcome used in trauma epidemiology as it is assumed that death after this milestone is generally caused by factors other than the traumatic incident. Other operational, demographic and performance indicators were extracted from the respective trauma databases in aggregate form including age, gender, type of injury, ISS, systolic blood pressure, Glasgow Coma Scale (GCS) score, shock index, external cause of injury, transport platform, ambulance time intervals, level of prehospital care, airway intervention (laryngeal mask airway, oral pharyngeal tube, endotracheal tube or King laryngeal tube airway), intravenous line insertion and oxygen administration.

\section{Statistical methods}

Aggregate descriptive statistics were calculated using data from each trauma registry. Cases with missing fields were not included in the statistical analysis. For this reason, there is a $(n=)$ value expressed in the tables for variables calculated from fewer cases than the total cohort. The sample size available for analysis was determined by the number of patients who met our inclusion criteria during the study period. The aggregate results from each registry were compared using an array of Fisher's exact tests for categorical data as well as t tests for continuous data. A power analysis was performed using regression analysis.

\section{RESULTS \\ Power analysis}

To address power in our study, and to be able to account for the differences between and within categories of data, we performed two mixed $\log$ regressions for data included in tables 1 and 2 as well as a Poisson regression for data included in table 3. Each regression analysis compared the two groups (BEMS and AEMS). The first regression compared the nine independent variables from table 1 (ISS by category, age, gender, type of injury, ISS, external cause of injury, systolic blood pressure, GCS, shock index). The eight independent variables (transport platform, on scene provider, three time intervals and three interventions) in table 2 were used for the second regression analysis. In the Poisson regression, the three injury severity categories were compared. A small effect size $\left(f^{2}=0.10\right)$ and a significant size difference of slopes fixed at 0.05 give a power of $84 \%$ when the sample size is 274 from AEMS and 111 from BEMS. Due to a smaller sample size available (251 from AEMS and 101 from BEMS), the actual power (post-test) reduced to $71 \%$ for the regression test based on table 1 , but remained at an acceptable level $(77 \%)$ for table 2 , and even improved (82\%) for table 3. Regression tests have the advantage of low probabilities for type 1 errors, a very appealing feature in Medical and Health studies.

\section{Comparison of baseline group characteristics}

A total of 352 patients were included in the study. There were 251 (71\%) patients treated in the AEMS, compared with 101 (29\%) patients who were treated in the BEMS (figure 2).

Table 1 describes demographic and injury characteristics of all patients included in the study. The majority of characteristics were similar between the model systems. Patient age, gender, type of injury, median ISS and median GCS score were not significantly different when comparing the overall cohorts. Differences in median and IQR ISS emerged when the cohorts were subdivided into moderately injured patients (ISS 13-24) and severely injured patients (ISS $>24$ ). The severely injured patients in the AEMS had a significantly higher median ISS compared with patients in the BEMS $(p=0.019)$. There were also differences in the mechanical causes of injury in each group. There was a lower proportion of falls (from any height) in the AEMS group compared with the BEMS group $(p=0.015)$, a higher proportion of transport accidents in the AEMS when compared with the 


\begin{tabular}{|c|c|c|c|c|c|c|c|c|c|}
\hline \multirow[t]{2}{*}{ Characteristic } & \multicolumn{3}{|c|}{ Emergency Medical System } & \multirow[t]{2}{*}{ Outcome } & \multicolumn{5}{|c|}{ Emergency Medical System } \\
\hline & Basic & Advanced & p Value & & Basic n (\%) & Advanced n (\%) & OR & $95 \% \mathrm{Cl}$ & p Value \\
\hline Overall & $n=101$ & $n=251$ & & Overall & $n=101$ & $n=251$ & & & \\
\hline $\begin{array}{l}\text { Transport platform, n (\%) } \\
\text { transferred by air }\end{array}$ & $0(0)$ & $30(12)$ & & $\begin{array}{l}\text { Survival to } \\
\text { hospital }\end{array}$ & $97(96)$ & $232(92)$ & 1.98 & 0.66 to 5.99 & 0.34 \\
\hline ALS provider on scene, $n(\%)$ & $0(0)$ & $232(92)$ & & Survival to & $85(84)$ & $195(78)$ & 1.53 & 0.83 to 2.81 & 0.19 \\
\hline \multicolumn{4}{|l|}{ Time intervals (min), median (IQR) } & discharge or & & & & & \\
\hline \multirow[t]{2}{*}{ Response interval } & $\mathrm{n}=97$ & $n=234$ & & 30 days & & & & & \\
\hline & $8(5-14)$ & $9(6-14)$ & 1.00 & $\begin{array}{l}\text { Moderate } \\
\text { iniuries }\end{array}$ & $\mathrm{n}=68$ & $\mathrm{n}=171$ & & & \\
\hline \multirow[t]{2}{*}{ On scene interval* } & $\mathrm{n}=95$ & $n=233$ & & Survival to & $66(97)$ & 161 (01) & 205 & & \\
\hline & $18(12-24)$ & $23(16-34)$ & 0.002 & hospital & $00(91)$ & $101(94)$ & 2.05 & 0.44 to 9.01 & 0.90 \\
\hline \multirow[t]{2}{*}{ Total prehospital interval } & $n=97$ & $n=212$ & & \multirow{3}{*}{$\begin{array}{l}\text { Survival to } \\
\text { discharge or } \\
30 \text { days }\end{array}$} & \multirow{3}{*}{$65(96)$} & \multirow[t]{3}{*}{$150(88)$} & \multirow[t]{3}{*}{3.03} & \multirow[t]{3}{*}{0.87 to 10.53} & \multirow[t]{3}{*}{0.47} \\
\hline & $52(39-68)$ & $51(37-71.3)$ & 0.85 & & & & & & \\
\hline Prehospital interventions, n (\%) & $\mathrm{n}=97$ & $n=251$ & & & & & & & \\
\hline Airway intervention* & $4(4)$ & $38(15)$ & 0.003 & Severe injuries & $n=33$ & $\mathrm{n}=80$ & & & \\
\hline Intravenous line insertions* & $31(32)$ & $195(78)$ & $<0.001$ & \multirow{2}{*}{$\begin{array}{l}\text { Survival to } \\
\text { hospital }\end{array}$} & \multirow[t]{2}{*}{31 (94) } & \multirow[t]{2}{*}{$71(89)$} & \multirow[t]{2}{*}{1.96} & \multirow[t]{2}{*}{0.40 to 9.63} & \multirow[t]{2}{*}{0.50} \\
\hline Oxygen administration & $71(73)$ & $165(66)$ & 0.20 & & & & & & \\
\hline Moderate injury & $n=68$ & $n=171$ & & \multirow{2}{*}{$\begin{array}{l}\text { Survival to } \\
\text { discharge or } \\
30 \text { days }\end{array}$} & \multirow[t]{2}{*}{$20(61)$} & \multirow[t]{2}{*}{$45(56)$} & \multirow[t]{2}{*}{1.20} & \multirow[t]{2}{*}{0.52 to 2.73} & \multirow[t]{2}{*}{0.83} \\
\hline $\begin{array}{l}\text { Transport platform, n (\%) } \\
\text { transferred by air }\end{array}$ & $0(0)$ & $16(9)$ & & & & & & & \\
\hline
\end{tabular}

BEMS ( $p=0.003)$ and a lower proportion of patients injured by animate or inanimate forces in the AEMS compared with the BEMS $(\mathrm{p}=0.041)$.

\section{Comparison of care delivered}

A comparison of system characteristics and care delivery is provided in table 2. In the AEMS, there was at least one paramedic trained at the ACP level who was capable of delivering ALS care on scene in $92 \%$ of cases. In the AEMS, $15 \%$ of patients received an airway intervention compared with $4 \%$ in the BEMS $(\mathrm{p}=0.0032)$ and $78 \%$ of patients had an intravenous line inserted compared with $32 \%$ in the BEMS $(p<0.0001)$. Paramedics spent more time on scene in the AEMS, with a median of $23 \mathrm{~min}$ (IQR 16-34) compared with $18 \mathrm{~min}$ (IQR $12-24)$ in the BEMS $(p=0.0021)$ (see figure 3$)$. However, there was no difference in total prehospital time between the AEMS and the BEMS (median $51 \mathrm{~min}$, IQR $37-71.3$ vs $52 \mathrm{~min}$, IQR $39-68, \mathrm{p}=0.8453)$.

\section{Comparison of outcomes}

The overall mortality was low, 329 of 352 (93\%) patients survived to hospital and 280 of $352(80 \%)$ patients survived to discharge or 30 days. There were no statistically significant survival differences observed between the AEMS and BEMS groups (table 3). Patients were equally likely to survive to hospital in the AEMS (232/251, 92\%) compared with the BEMS (97/101, 96\%; OR $1.98,95 \%$ CI 0.66 to $5.99 ; \mathrm{p}=0.34)$. Furthermore, patients in the AEMS $(195 / 251,78 \%)$ were equally likely to survive to 30 days or discharge from hospital compared with patients in the BEMS $(85 / 101,84 \%$; OR $1.53,95 \%$ CI 0.83 to $2.81 ; \mathrm{p}=0.19)$. When the cohorts were grouped according to injury severity, again there were no observed survival differences, even in those with severe injuries, for both survival to hospital $(71 / 80,89 \%$ vs $31 / 33,94 \%$; OR $1.96,95 \% \mathrm{CI} 0.40$ to $9.63 ; \mathrm{p}=0.50)$ and for survival to 30 days or discharge $(45 / 80,56 \%$ vs $20 / 33,61 \%$; OR $1.20,95 \%$ CI 0.52 to $2.73 ; \mathrm{p}=0.83)$.

\section{DISCUSSION}

The goal of this study was to determine if treatment in an advanced prehospital emergency care system provided a survival benefit to patients with trauma compared with a basic prehospital emergency care system. Based on a study population of 352 patients with trauma, no survival differences were found between these two systems. This supports the findings of other researchers who examined the effects of prehospital trauma care in Canadian cities, ${ }^{717}$ as well as abroad. ${ }^{18} 19$ 


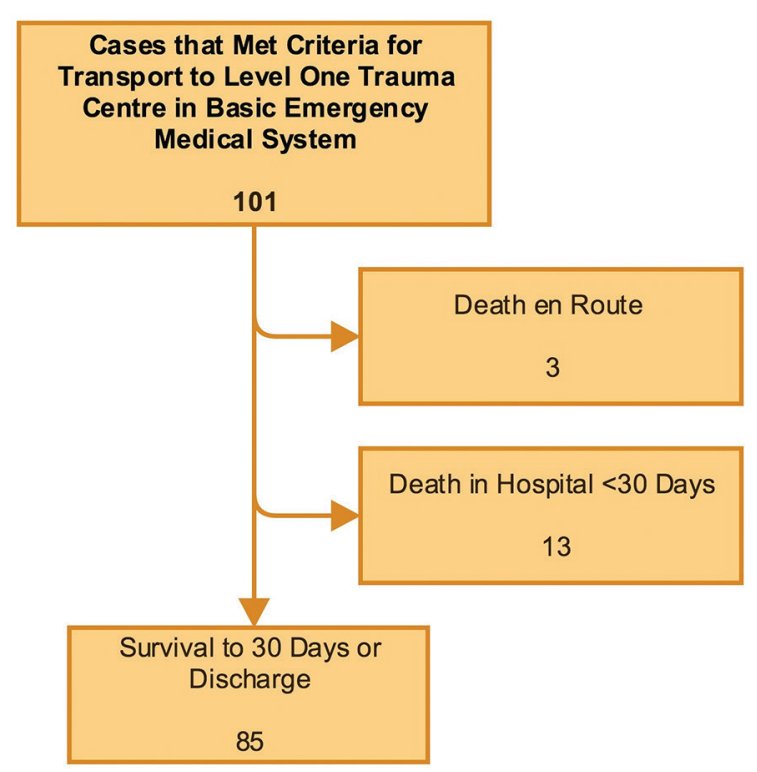

Figure 2 Flow diagrams demonstrating transport and survival.

The gold standard for evaluating the effectiveness of a medical intervention is a systematic review of methodologically robust randomised control trials. Only two published randomised control trials have investigated the effect of provider level on outcomes in patients with major trauma. ${ }^{20}$ Although both these studies showed a likely benefit, they were focused on patients with head injuries and neither study compared ALS with BLS care delivered by paramedics.

Internationally, there has been evidence that ALS procedures in the prehospital setting such as endotracheal intubation can actually increase mortality in patients with trauma. ${ }^{22-24}$ It is possible that an intervention designed predominantly to treat medical emergencies such as acute asthma, anaphylaxis, chest pain or cardiac arrest has questionable utility for patients with trauma where the critical disease process is often life-threatening haemorrhage.

Our analysis of system characteristics in New Brunswick and Nova Scotia demonstrated that $92 \%$ of patients with trauma in the advanced system received care from an ALS provider. In the basic system, all paramedics were mandated to operate at the PCP level regardless of their level of training. The provision of procedures including airway interventions and intravenous cannulation were increased in the advanced system. It does not

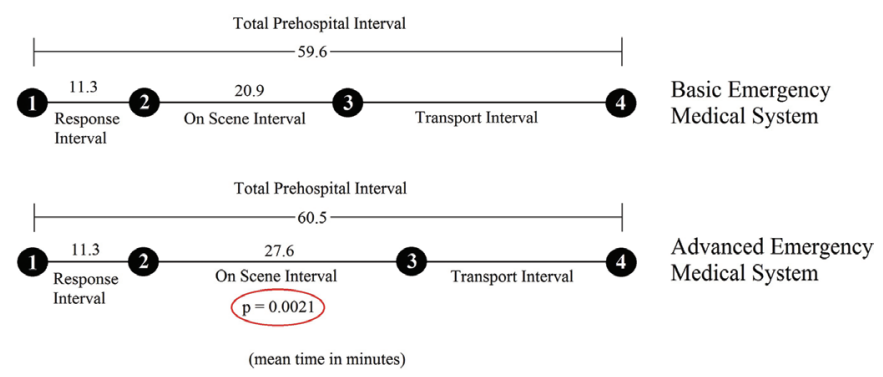

Figure 3 Prehospital time intervals displayed as means in minutes with numbered circles indicating specific points in time: 1: time call received by ambulance dispatch; 2 : ambulance arrives at scene; 3 : ambulance departs scene; 4 : patient arrives at trauma centre. The highlighted $p$ value represents the difference in on scene interval observed between systems.

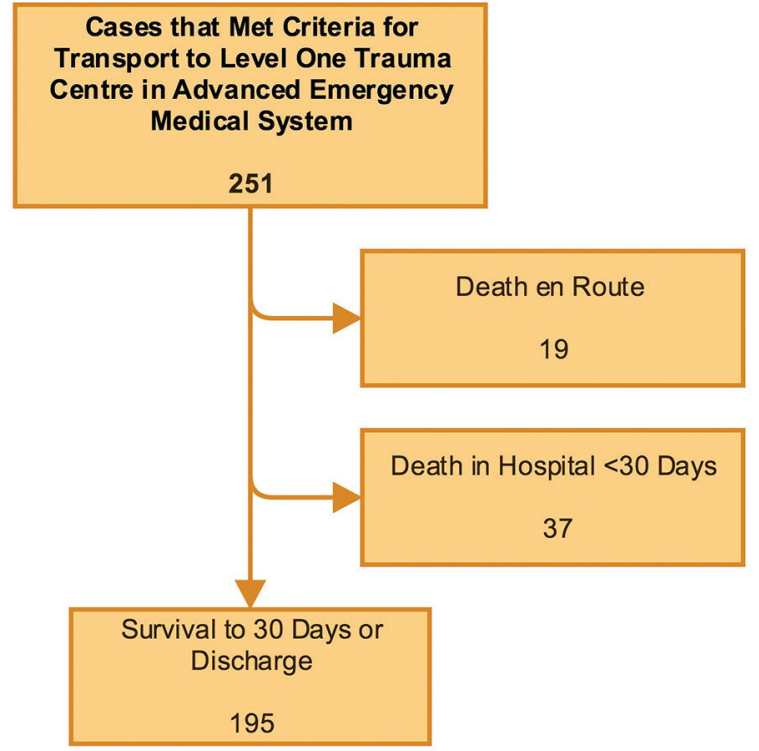

appear that these systemic differences provide survival benefit when applied broadly to patients with trauma.

It has been suggested that a major pitfall of ALS is prolonged on scene intervals that delay patient transfer to hospital. Although our study demonstrated increased scene time in the AEMS, there was no survival benefit for patients treated in the BEMS with shorter on scene times. McCoy et $a l^{25}$ suggest that on scene intervals greater than $20 \mathrm{~min}$ increase mortality in patients with penetrating trauma but not blunt trauma. ${ }^{25}$ Since the majority of patients in our study suffered blunt injuries, it is consistent that differences in scene time did not affect survival. Despite increased scene times in the AEMS, the total prehospital interval was similar indicating that more time was spent in transport in the BEMS. Possible reasons for this include the increased population density in the Halifax region leading to a higher likelihood of injury near the level 1 trauma centre, as well as the use of helicopters in the transportation of patients in the AEMS.

It was hypothesised that if survival differences existed between systems, they would be most apparent in the comparison of severely injured patients given that these patients would theoretically receive the most benefit from provision of ALS. Contrary to our hypothesis, there was no overall crude survival difference, nor was there a survival difference in severely injured patients in this unmatched cohort with no case mix adjustment.

The questions that remain are whether this was a true finding, was our sample size too small and did the groups differ too much in demographics for any meaningful comparison? Alternatively, it could be argued that comparison should be between patients in the BEMS and only those patients in the advanced system cohort who had access to meaningful trauma interventions. These remaining questions give us precedence to request case-level data from the provincial trauma registries so that more robust analysis can be performed to account for any confounding variables that may have affected our results.

The findings of our study should be interpreted with caution. Although regression analysis was performed, our results are dependent on unmatched aggregate data, which precluded our ability to adjust for potential confounding factors. Case-level data would allow for more robust adjustment for the effects of age, injury severity, physiology, injury mechanism and comorbidity. 
Another limitation was the relatively small sample size available for the number of hypothesis tests conducted. This was particularly limiting in the subgroup analysis where the sample size was reduced to stratify patients based on injury severity. Although baseline characteristics of the two groups were similar, differences in injury severity and mechanism of injury could be suppressing any effect in the observed crude outcome. As with all retrospective cohort studies, there is potential risk of selection bias. However, the trauma databases drawn from in this study each have their own robust internal auditing processes and should capture the majority of patients that meet criteria for inclusion into their respective databases.

\section{CONCLUSION}

In this registry cohort study of patients transported to two Canadian level 1 trauma centres, we found no difference in primary outcome between patients with trauma cared for in an AEMS when compared with those receiving care in a BEMS. Although no mortality difference was observed on a system level, we are unable to say that the provision of ALS provided no benefit to individual patients. There is a large amount of heterogeneity in patients with trauma that cannot be accounted for simply by looking at measures such as ISS and GCS. The majority of patients that are injured are not at significant risk of death. Although their injuries are unlikely to be fatal, they do cause significant pain and possible disability. Similar to Moore et al, we recommend further development and implementation of validated non-fatal outcome measures in trauma care systems. ${ }^{26}$ Outcomes such as patient function, analgesia, awareness of suffering and quality of life are as important as mortality but are largely unreported in the current literature.

Contributors All authors were involved in the planning of the research. The manuscript proposal was written by CR and JH under the guidance of JFrench, PA and RG. Navigation of the trauma systems in each province and planning for collaboration was facilitated by IW, SB, ME and RG. Data acquisition was performed by BS and AC. Statistical support was provided by GS. Overall co-ordination was performed by JFraser. The manuscript was written by $C R$ with revisions provided by ME, PA, JH, JFrench, IW, SB and RG. All authors approved the final manuscript.

Funding The two primary authors received funding from Dalhousie University Faculty of Medicine New Brunswick. The Summer Student Research Program Studentship allowed them to complete research during a summer session of their undergraduate medical education. The study sponsor had no role in the study design; in the collection, analysis and interpretation of the data; in the writing of the report; or in the decision to submit the paper for publication. IW reports a potential competing interest from the New Brunswick Trauma Program. During the conduct of the study, he had a salaried position with the New Brunswick Trauma Program. SB reports a potential competing interest from the New Brunswick Trauma Program. During the conduct of the study, she had a salaried position with the New Brunswick Trauma Program.

Competing interests IW reports a potential competing interest from the NB Trauma Program. During the conduct of the study he had a salaried position with the New Brunswick Trauma Program. SB reports a potential competing interest from the NB Trauma Program. During the conduct of the study she had a salaried position with the New Brunswick Trauma Program.

Patient consent Detail has been removed from this case description/these case descriptions to ensure anonymity. The editors and reviewers have seen the detailed information available and are satisfied that the information backs up the case the authors are making.
Ethics approval Horizon Health Network Research Ethics Board, Nova Scotia Health Authority Research Ethics Board.

Provenance and peer review Not commissioned; externally peer reviewed.

(c) Article author(s) (or their employer(s) unless otherwise stated in the text of the article) 2018. All rights reserved. No commercial use is permitted unless otherwise expressly granted.

\section{REFERENCES}

1 World Health Organization. Injuries and Violence: The Facts. Geneva: WHO, 2014.

2 Cardinal M, Crain J, Do MT, et al. Report summary - injury in review, 2012 edition: spotlight on road and transport safety. Chronic Dis Inj Can 2012;32:229-30.

3 Sahai VS, Ward MS, Zmijowskyj T, et al. Quantifying the iceberg effect for injury: using comprehensive community health data. Can J Public Health 2005;96:328-32.

4 Ryynänen OP, lirola T, Reitala J, et al. Is advanced life support better than basic life support in prehospital care? a systematic review. Scand J Trauma Resusc Emerg Med 2010;18:62-14.

5 Isenberg DL, Bissell R. Does advanced life support provide benefits to patients?: a literature review. Prehosp Disaster Med 2005:20:265-70.

6 von Vopelius-Feldt J, Wood J, Benger J. Critical care paramedics: where is the evidence? a systematic review. Emerg Med J 2014;31:1016-24.

7 Stiell IG, Nesbitt LP, Pickett W, et al. The OPALS major trauma study: impact of advanced life-support on survival and morbidity. CMAJ 2008;178:1141-52.

8 Meizoso JP, Valle EJ, Allen CJ, et al. Decreased mortality after prehospital interventions in severely injured trauma patients. J Trauma Acute Care Surg 2015;79:227-31.

9 Bushby N, Fitzgerald M, Cameron P, et al. Prehospital intubation and chest decompression is associated with unexpected survival in major thoracic blunt trauma. Emerg Med Australas 2005;17:443-9.

10 Arbabi S, Jurkovich GJ, Wahl WL, et al. A comparison of prehospital and hospital data in trauma patients. J Trauma 2004;56:1029-32.

11 Liberman M, Mulder D, Sampalis J. Advanced or basic life support for trauma: metaanalysis and critical review of the literature. J Trauma 2000;49:584-99.

12 Bakalos G, Mamali M, Komninos C, et al. Advanced life support versus basic life support in the pre-hospital setting: a meta-analysis. Resuscitation 2011;82:1130-7.

13 Hayre J, Rouse C, French J, et al. A traumatic tale of two cities: a comparison of outcomes for adults with major trauma who present to differing trauma centres in neighbouring Canadian provinces. CJEM 2017:1-9.

14 Personal Health Information Privacy and Access Act. Queen's Printer for New Brunswick, SNB, c P-7, 2009. http://canlii.ca/t/52wbf (accessed 28 Feb 2017).

15 Statistics Canada. Census of population, 2011: Census Tract (CT) profiles. 2011 http:// www12.statcan.gc.ca/census-recensement/2011/ (accessed Apr 2016).

16 National occupational competency profile for paramedics. Paramedic Association of Canada, 2011.

17 Liberman M, Mulder D, Lavoie A, et al. Multicenter canadian study of prehospital trauma care. Ann Surg 2003;237:153-60.

18 Di Bartolomeo S, Sanson G, Nardi G, et al. A population-based study on pneumothorax in severely traumatized patients. J Trauma 2001;51:677-82.

19 Sanghavi $P$, Jena AB, Newhouse JP, et al. Outcomes of basic versus advanced life support for out-of-hospital medical emergencies. Ann Intern Med 2015;163:681-90.

20 Baxt WG, Moody P. The impact of a physician as part of the aeromedical prehospital team in patients with blunt trauma. JAMA 1987;257:3246-50.

21 Garner AA, Mann KP, Fearnside M, et al. The Head Injury Retrieval Trial (HIRT): a single-centre randomised controlled trial of physician prehospital management of severe blunt head injury compared with management by paramedics only. Emerg Med J 2015;32:869-75.

22 Davis DP, Hoyt DB, Ochs M, et al. The effect of paramedic rapid sequence intubation on outcome in patients with severe traumatic brain injury. J Trauma 2003;54:444-53.

23 Eckstein M, Chan L, Schneir A, et al. Effect of prehospital advanced life support on outcomes of major trauma patients. J Trauma 2000;48:643-8.

24 Davis DP, Peay J, Sise MJ, et al. The impact of prehospital endotracheal intubation on outcome in moderate to severe traumatic brain injury. J Trauma 2005;58:933-9.

25 McCoy CE, Menchine M, Sampson S, et al. Emergency medical services out-of-hospital scene and transport times and their association with mortality in trauma patients presenting to an urban Level I trauma center. Ann Emerg Med 2013;61:167-74.

26 Moore L, Stelfox HT, Boutin A, et al. Trauma center performance indicators for nonfatal outcomes: a scoping review of the literature. J Trauma Acute Care Surg 2013;74:1331-43. 